\title{
Two-step two-stent technique to manage a large gastrocolonic fistula
}

Gastrocolonic malignant fistulas can occur, although rarely, complicating gastric or colonic neoplasms. En bloc resection of the fistulous tract and involved segments is the first-line treatment whenever possible, with endoscopic treatment an alternative. Endoscopic closure has been described using covered stents $[1,2]$, over-the-scope clips [3], and atrial septal defect occlusion devices [4]. However, in the colon, covered stents are associated with a high migration risk [5]. We therefore developed a new technique to allow fistula closure, overcoming the risks of stent migration by initially placing an uncovered stent, which is followed by the deployment of a covered stent inside the first stent a few days later and fixation of the two stents to each other using through-the-scope clips.

Our patient, a 58-year-old woman, had a metastatic and locally advanced intestinal-type gastric cancer with colonic invasion. After receiving 12 cycles of palliative chemotherapy, she was admitted with fecaloid emesis and a computed tomography (CT) scan showed a large fistulous tract (approximately $5 \mathrm{~cm}$ in length with a large orifice) between the stomach and the transverse colon. Although the patient had a good performance status, surgical resection was not considered feasible and endoscopic palliation was proposed.

Esophagogastroduodenoscopy (EGD) showed a large ulcerated neoplasm in the greater curvature of the gastric antrum, with a large orifice communicating with an ulcerated fistulous tract. Colonoscopy revealed a stenosis in the transverse colon and contrast instillation allowed characterization of the stricture and of the fistulous tract. An uncovered metal stent (WallFlex; 22-27 mm $\times 90 \mathrm{~mm}$; Boston Scientific, Marlborough, Massachusetts, USA) was then placed in the strictured transverse colon where the colonic fistulous orifice was located. After 3 days (to allow time for embedment of the uncovered stent in the colonic wall), a similar

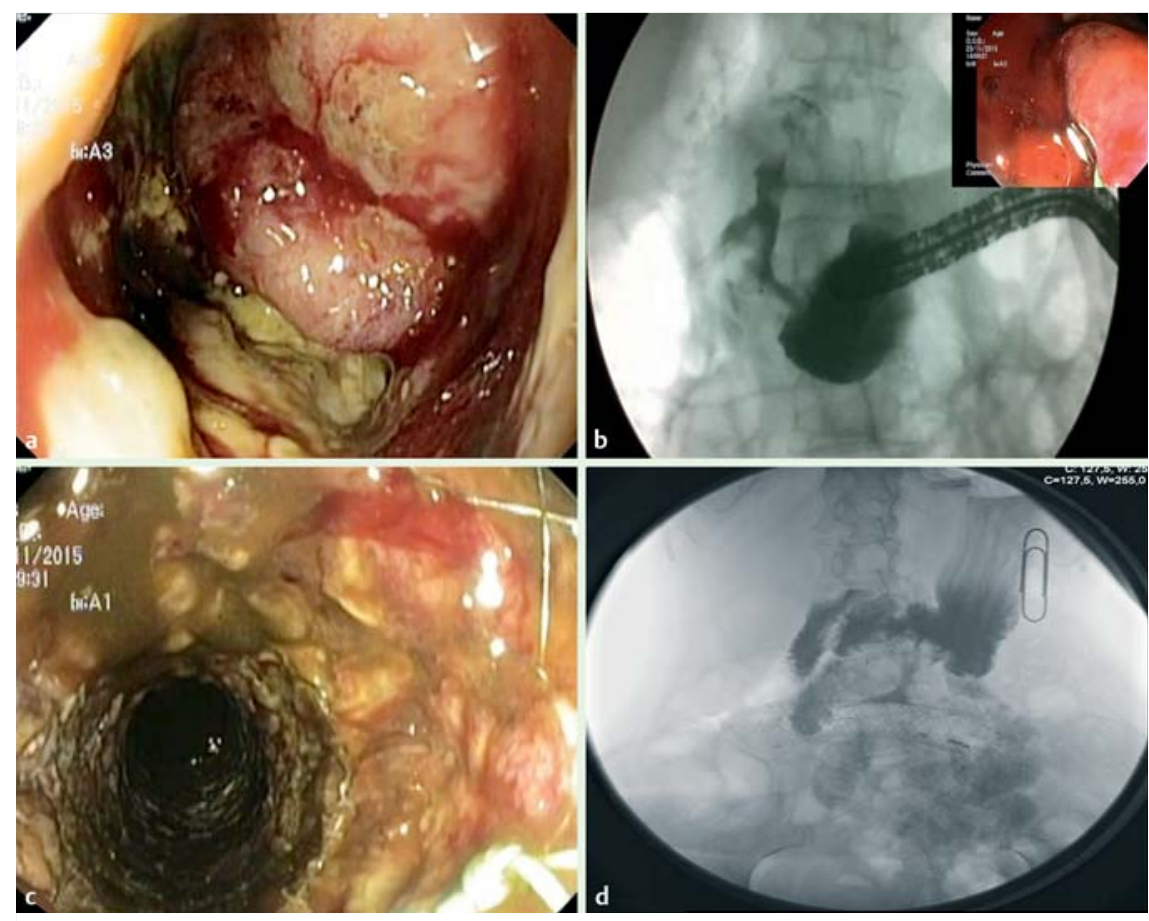

- Fig. 1 Endoscopic and fluoroscopic images showing a partially covered stent that was placed inside a previously deployed uncovered colonic stent to provide endoscopic closure of a large gastrocolonic fistulous tract.

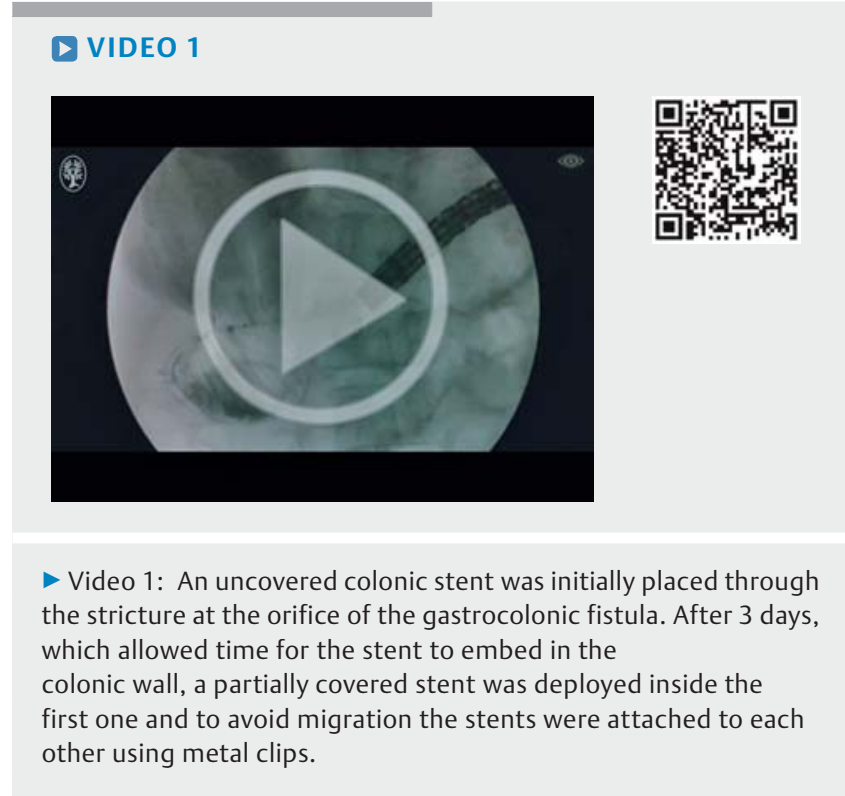


caliber partially covered stent (Hanarostent; 26-20-26 mm ×90 mm; M. I. Tech, Pyeongtaek-si, Gyeonggi, South Korea) was deployed inside the previously placed stent in order to occlude the fistulous tract. Finally, the meshes of the two metal stents were fixed to each other with two metal clips ( $>$ Fig. 1 ; $>$ Video 1 ).

This innovative approach allowed the fistulous tract to be closed, as seen in a gastroduodenal series performed after 3 days, and the patient was discharged 3 days later on an oral diet. Closure of the fistula allowed the patient's palliative chemotherapy to be continued and 6 months later she was still alive, without any fistula-related symptoms and with the stents in place. We believe that this technique should be considered to decrease the risk of migration whenever an enteral covered stent is needed to occlude a fistulous tract or dehiscence.

Endoscopy_UCTN_Code_TTT_1AQ_2AG

\section{Competing interests}

None

The Authors

Diogo Libânio, Jorge Lage, Sara Pires, Rui Silva, Mário Dinis-Ribeiro

Gastroenterology Department, Portuguese

Oncology Institute of Porto, Porto, Portugal

Corresponding author

\section{Diogo Libânio, MD}

Gastroenterology Department, Portuguese Oncology Institute of Porto, Rua Dr. António Bernardino de Almeida, 4200-072 Porto, Portugal,

diogolibaniomonteiro@gmail.com

\section{References}

[1] Fernandes C, Pinho R, Proenca L et al. Palliation of a gastrocolic fistula secondary to colon cancer with a covered colonic stent using a simultaneous dual-scope approach. Tech Coloproctol 2015; 19: 367-368

[2] Lim CH, Kim SW, Kim JS et al. Successful palliation of a gastrocolic fistula secondary to gastric cancer by insertion of a covered colonic stent. Gastrointest Endosc 2011; 73 : $1314-1317$

[3] Monkemuller K, Peter S, Alkurdi B et al. Endoscopic closure of a gastrocolic fistula using the over-the-scope-clip-system. World J Gastrointest Endosc 2013; 5: 402 406

[4] Malespin M, Gaspar JP, Boulay B. Palliation of a malignant gastrocolic fistula with the use of an atrial septal defect occlusion device. Endoscopy 2014; 46 (Suppl. 01): E4

[5] Choi JH, Lee Y], Kim ES et al. Covered selfexpandable metal stents are more associated with complications in the management of malignant colorectal obstruction. Surg Endosc 2013; 27: 3220 - 3227

\section{Bibliography}

DOI http://dx.doi.org/10.1055/s-0042-118456 Endoscopy 2017; 49: E7-E8

(c) Georg Thieme Verlag KG

Stuttgart · New York

ISSN 0013-726X 